\title{
Arte urbano como patrimonio cultural. Galería Vertical como referente en Reinosa
}

\author{
Francisco Javier Ostos Prieto | Arquitecto \\ URL de la contribución <www.iaph.es/revistaph/index.php/revistaph/article/view/4876>
}

Las manifestaciones artísticas en el espacio urbano no siempre son bien recibidas por la población o las instituciones, constituyendo un constante objeto de debate. En algunas situaciones la postura de la prensa, desde un enfoque negativo del arte urbano, ha podido condicionar la opinión ciudadana (San Juan Fernández 2018, 191). La cultura del arte urbano no nace y tiene un desarrollo aislado, sino que establece relaciones con la ciudad, los agentes políticos y sobre todo sociales (Chaves Martín 2014, 279). El espacio público constituye un contenedor de arte urbano haciendo que estas expresiones artísticas formen parte de la propia ciudad. En la contemporaneidad se ha apostado por la creación de barrios artistas y galerías urbanas como regeneradores y rehabilitadores de espacios de la ciudad (Chaves Martín 2014, 280). Ante la degradación de algunas áreas urbanas o ante una reinvención de las mismas, el arte urbano ofrece nuevas posibilidades para la reactivación a través de la intervención artística.

En grandes ciudades, el arte urbano ha prosperado hasta el punto de convertirse en uno de sus principales atractivos. Un destacado ejemplo lo constituye VitoriaGasteiz, cuya Galería de Arte Mural es reconocida internacionalmente siendo además uno de los motivos para su nombramiento como Capital Verde Europea en 2012 (Villagos 2019, 4). No obstante, mientras que en grandes aglomeraciones urbanas el arte urbano tiene una mayor repercusión y es aceptado como seña cultural, ¿sería posible una consideración patrimonial en poblaciones de menor escala?

Uno de los ejemplos paradigmáticos en la reflexión sobre arte urbano como patrimonio lo constituye el municipio de Reinosa, en Cantabria. Se trata de una pequeña localidad de 8.946 habitantes (INE 2020), en la comarca de Campoo-Los Valles. Su morfología urbana es similar a la de sus semejantes cántabras de la región. Sin embargo, Reinosa está caracterizada por un enriquecimiento artístico de su espacio urbano. Al ser una pequeña población, no existe una "zonificación" de este tipo de expresiones, sino que se distribuyen por todo el municipio. Así pues, ¿no supondría esta "invasión" una agresión hacia el municipio?

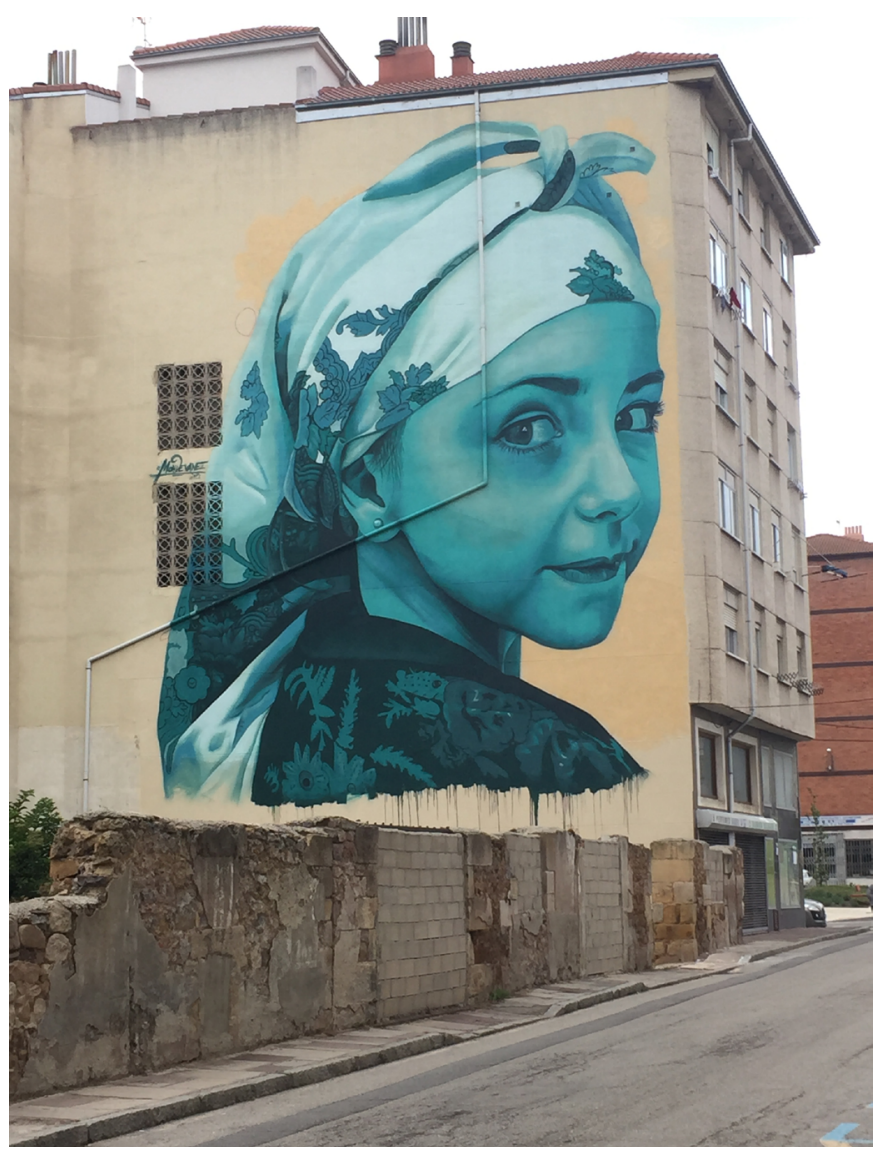

Mural Niña Campurriana, por Mon Devane | Francisco Javier Ostos Prieto 




Mural Nacimiento del Ebro, por Néstor del Barrio | foto Francisco Javier Ostos Prieto

El éxito de experiencias como la de Vitoria-Gasteiz y otras similares impulsa en 2016 una iniciativa cultural promovida por Almudena Báscones junto al Ayuntamiento de Reinosa, denominada Galería Vertical. Báscones plantea tres objetivos como base del proyecto: sacar el arte a la calle, hacerlo visible y público; ofrecer a artistas un soporte para poder expresarse; y conformar, a través del arte, una ruta artística que atraiga mayor turismo cultural a la zona (Tag: Galeria Vertical 2021). Sus inicios quedaron marcados por la búsqueda de una experiencia artística participativa grupal (Crespo Martín 2019, 276) junto a los estudiantes del Colegio Antares, que trabajaron para dejar su huella artística en el mobiliario urbano, como bancos y papeleras.
Cinco años después, Galería Vertical ha generado la incorporación de más de 30 murales al proyecto e intervención de artistas en el patrimonio artístico de Reinosa. Al emplear elementos urbanos como fachadas, medianeras, muros, etc., las actuaciones han repercutido positivamente en el espacio público. Además, han supuesto un atractivo para artistas de reconocido prestigio, como Okuda o Jay Kaes. En este tipo de intervenciones, aunque la temática es totalmente libre, muchos creadores han optado por la búsqueda de inspiración en el patrimonio etnológico y natural de la región. Es el caso de Mon Devane, que emplea la imagen tradicional de la niña campurriana como motivo de expresión artística, imagen que actualmente ha pasado a ser un símbolo reconoci- 
ble de Reinosa. A su vez, Néstor del Barrio ha empleado el icónico espacio natural del nacimiento del río Ebro para su obra. De este modo, al encontrar la inspiración en el patrimonio local se consigue que este quede plasmado visualmente en el propio municipio como eco de sus tradiciones.

Actualmente, el proyecto Galería Vertical constituye un verdadero referente artístico. Tanto es así que, según datos de la oficina de turismo de Reinosa referidos a 2019, la demanda turística se relaciona, además de, como venía siendo habitual, con el interés patrimonial de las iglesias rupestres, la ciudad romana de Julióbriga, el castillo de Argüeso o el nacimiento del Ebro, también con el arte urbano reinosano. De hecho, según la oficina de turismo, hubo una gran demanda de visitas guiadas a los murales, lo que consolida el tercer objetivo de Báscones para el proyecto. La otrora consideración "agresiva" que pudiera haber en Reinosa del arte urbano, producida generalmente en su uso de la propiedad privada, más que por cuestiones estéticas (San Juan Fernández 2018, 200), queda prácticamente diluida por Galería Vertical. La iniciativa conjunta de artistas y gobierno local ha derivado en la aceptación del uso del espacio público para la actividad artística. Este hecho, sumado a que la población local lo perciba con agrado, ha permitido que los ciudadanos de Reinosa sientan el arte como propio, viendo incluso sus tradiciones y cultura representados en él, hasta el punto de considerar los murales reinosanos como un nuevo patrimonio cultural de la localidad. Cuando el pueblo se identifica con las expresiones artísticas, es cuando se efectúa el paso para considerarlas patrimonio cultural.

\section{BIBLIOGRAFÍA}

- Chaves Martín, M.A. (2014) Artistas y espacio urbano: la representación de la ciudad en el arte contemporáneo. Historia y Comunicación Social, vol. 19, pp. 277-288. Disponible en: http://dx.doi.org/10.5209/rev_HICS.2014.v19.45132 [Consulta: 24/03/2021]

- Crespo Martín, B. (2019) Acerca de las prácticas artísticas participativas contemporáneas como catalizadoras de la sociabilización. Historia y Comunicación Social, vol. 25, pp. 275-286. Disponible en: http://dx.doi.org/10.5209/hics.69244 [Consulta: 24/03/2021]

- INE (2020) Cifras oficiales de población resultantes de la revisión del Padrón municipal a 1 de enero (población de Reinosa en 2020). Disponible en: https://www.ine.es/jaxiT3/ Datos.htm?t=2893 [Consulta: 20/03/2021]

- Oficina de Turismo (2021) Ayuntamiento de Reinosa. Disponible en: https://www.aytoreinosa.es/cpt_services/ oficina-de-turismo/ [Consulta: 20/03/2021]

- San Juan Fernández, J. (2018) Grafiti y arte urbano: una propuesta patrimonial de futuro. Santander. Estudios de Patrimonio, n. ${ }^{\circ}$ 1, pp. 181-210. Disponible en: https://doi. org/10.22429/Euc2018.sep.01.05 [Consulta: 24/03/2021]

- Tag: Galeria Vertical (2021) Ayuntamiento de Reinosa. Disponible en: https://www.aytoreinosa.es/tag/galeria-vertical/ [Consulta: 20/03/2021]

- Villajos, S., Werckmeister, V. y García, L. (2019) Street Art and Intangible Heritage: a contextualising approach to public art in Vitoria-Gasteiz. On the W@terfront, vol. 61, n. ${ }^{\circ}$ 5, pp. 3-29. Disponible en: https://doi.org/10.1344/waterfront2019.61.6.6 [Consulta: 20/03/2021] 